\title{
Spectral Peak Frequency in Low-Frequency Band in Cross Spectra of Blood Pressure and Heart Rate Fluctuations in Young Type 1 Diabetic Patients
}

\author{
N. HONZÍKOVÁ ${ }^{1}$, A. KRTIČKA ${ }^{1}$, E. ZÁVODNÁ ${ }^{1}$, M. JAVORKA ${ }^{2}$, I. TONHAJZEROVÁ ${ }^{2}$, \\ K. JAVORKA ${ }^{2}$
}

${ }^{1}$ Department of Physiology, Faculty of Medicine, Masaryk University, Brno, Czech Republic, ${ }^{2}$ Department of Physiology, Jessenius Faculty of Medicine, Comenius University, Martin, Slovak Republic

Received December 14, 2011

Accepted March 12, 2012

On-line June 6, 2012

\section{Summary}

In this study we tested whether joint evaluation of the frequency $\left(f_{c s}\right)$ at which maxima of power in the cross-spectra between the variability in systolic blood pressure and inter-beat intervals in the range of $0.06-0.12 \mathrm{~Hz}$ occur together with the quantification of baroreflex sensitivity (BRS) may improve early detection of autonomic dysfunction in type 1 diabetes mellitus (T1DM). We measured 14 T1DM patients (age 20.3-24.2 years, DM duration 10.4-14.2 years, without any signs of autonomic neuropathy) and 14 age-matched controls (Co). Finger arterial blood pressure was continuously recorded by Finapres for one hour. BRS and $f_{c s}$ were determined by the spectral method. Receiver-operating curves (ROC) were calculated for $f_{C S}$, BRS, and a combination of both factors determined as $F(z)=1 /(1+\exp (-z)), z=3.09-0.013 * B R S-$ $0.027 * f_{c s}$. T1DM had significantly lower $f_{c s}$ than Co (T1DM: $88.8 \pm 6.7$ vs. Co: $93.7 \pm 3.8 \mathrm{mHz} ; \mathrm{p}<0.05)$, and a tendency towards lower BRS compared to Co (T1DM: $10.3 \pm 4.4$ vs. Co: $14.6 \pm 7.1 \mathrm{~ms} / \mathrm{mm} \mathrm{Hg} ; \mathrm{p}=0.06)$. The ROC for Fz showed the highest sensitivity and specificity $(71.4 \%$ and $71.4 \%)$ in comparison with BRS (64.3\% and $71.4 \%)$ or $f_{c s}(64.3 \%$ and $64.3 \%)$. The presented method of evaluation of BRS and $f_{c s}$ forming an integrated factor $\mathrm{Fz}$ could provide further improvement in the risk stratification of diabetic patients.

\section{Key words}

Type 1 diabetes mellitus • Baroreflex sensitivity • Cross-spectral analysis • Frequency of spectral peak • Receiver operating curve

\section{Corresponding author}

N. Honzíková, Department of Physiology, Faculty of Medicine, Masaryk University, Kamenice 5, CZ-625 00 Brno, Czech Republic. E-mail: nhonziko@med.muni.cz

\section{Introduction}

Cardiovascular disease is the leading cause of mortality in adults with diabetes mellitus (Wadwa 2006). Especially, cardiovascular autonomic neuropathy (CAN) is a complication of diabetes mellitus which severely increases the mortality risk (Vinik et al. 2003), and therefore it has been tested for nearly 30 years (Ewing and Clarke 1982).

Recent studies show that subclinical signs of autonomic cardiovascular dysfunction could be found already in diabetic children without the diagnosis of cardiovascular neuropathy based on Ewing's tests (Javorka et al. 2011). The increased sympathetic and/or decreased parasympathetic control of heart rate and blood pressure at an early stage of CAN can be detected without the requirement of an active cooperation of the person tested. The application of spectral analysis to noninvasive recordings of blood pressure oscillations in finger arteries lasting for several minutes show that heart rate and blood pressure variability, and baroreflex sensitivity as well, are individually characteristic features of blood-pressure control (Honzíková et al. 1990, Jíra et al. 2006, 2010, Dietrich et al. 2010). Examination of heart rate and blood pressure variability brought evidence 
for an early increase of power of the low-frequency component in blood pressure spectra (Lucini et al. 2009), a decrease of the high-frequency component in the spectra of RR intervals (Laederach-Hofmann et al. 1999, Javorka et al. 2005, Krause et al. 2009), and suppressed baroreflex sensitivity (Krause et al. 2009, Lucini et al. 2009, Javorka et al. 2011) in diabetic patients.

A disturbance of the baroreflex loop can be characterized not only by its gain, e.g. baroreflex sensitivity, but also by a prolongation of the baroreflexloop time delay between oscillations in blood pressure and cardiac intervals assessed by a time-domain crosscorrelation method (Javorka et al. 2011).

The frequency at which baroreflex control of blood pressure operates can be supposed to be a third characteristic of this oscillating system, being possibly dependent on baroreflex control of peripheral resistance. This branch of baroreflex operates at a frequency of about $0.1 \mathrm{~Hz}$ (Sayers 1973, Wesseling et al. 1983). Penaz (1970) showed that the frequency response characteristics of resistance vessels in cat and rabbit to the stimulation of sympathetic nerves by a sinusoidally modulated frequency was dependent on the frequency of stimulation with the greatest gain in a range from 0.032 to $0.063 \mathrm{~Hz}$. Nakahara et al. (1999) measured the transfer function of the efferent peripheral sympathetic system and evaluated the amplitude and the phase shift of the frequency response of peripheral resistance. They found that this transfer function corresponds to a low-pass filter of the second order with a natural frequency between 0.05 and $0.09 \mathrm{~Hz}$ linked in series with a constant lag of $0.4 \mathrm{~s}$. Additionally, the frequency of the system resonance peak shifted to higher frequencies with increasing gain. They also showed that the administration of a neuronal uptake blocking agent at the neuroeffector junction decreased the dynamic gain and the natural frequency and prolonged the time lag of heart rate response on sympathetic stimulation. These data lead us to study the relationship between the heart-rate baroreflex sensitivity and the frequency of the feedback control of blood pressure, which includes association of variations in peripheral resistance and heart rate in the frequency range around $0.1 \mathrm{~Hz}$.

Until now, the information about the resonance frequency of the baroreflex control loop controlling peripheral vascular resistance was ignored, and therefore there is a lack of data on its possible changes in pathological circumstances. Therefore, in the present study we analysed whether evaluation of the frequency $\left(f_{c s}\right)$ at which maxima of power in the cross-spectra between the variability in blood pressure and inter-beat intervals in a frequency range of $0.06-0.12 \mathrm{~Hz}$ (lowfrequency band) together with the assessment of BRS could improve early detection of autonomic dysfunction in type 1 diabetes mellitus. Our analysis included not only the measurement of both parameters, $f_{c s}$ and BRS in diabetic patients and controls, but also analysis of correlation between both measures and determination of the sensitivity and specificity of each factor and their combination for discrimination between healthy controls and diabetic patients.

\section{Methods}

\section{Subjects}

We examined 14 patients with type 1 diabetes mellitus (T1DM) and 14 healthy controls of the same age and gender ( 7 women and 7 men in each group). All subjects were examined in the laboratory of the Department of Physiology, Jessenius Faculty of Medicine, Comenius University in Martin, Slovakia. The Michigan Neuropathy Screening Instrument (MNSI), composed of a history questionnaire and physical assessment (foot sensation), did not reveal neuropathy in any patient. Ankle reflexes were bilaterally present in all subjects. Standard monofilament sensation testing was performed at a pressure of 10 grams in ten separate places on both feet. All diabetic patients showed correct responses to these stimuli. The response for the Ewing battery of tests was also physiological (Javorka et al. 2011).

The patients with T1DM were aged 22.4 (20.3-24.2) years [median (interquartile range)]. They had hyperglycaemia $8.8(6.8-13.5) \mathrm{mmol} / \mathrm{l}$ and an increased HbA1c 9.7 (8.7-9.9) \%. The duration of diabetes mellitus was 12.9 (10.4-14.2) years; insulin was the only therapy used in the T1DM group. The mean age of the controls did not differ from the T1DM group - 21.4 (20.3-24.2) years, but plasma glucose $\left[\begin{array}{lll}4.9 & (4.3-5.1) & \mathrm{mmol} / \mathrm{l}\end{array}\right]$ and $\mathrm{HbAlc}$ [4.7 (4.5-5.0) \%] were significantly lower $(\mathrm{p}<0.001)$. No subject was treated by drugs affecting the cardiovascular system.

The Ethics Committee of Comenius University in Martin approved the study, and all participants of the study gave their consent.

Continuous blood pressure measurement, baroreflex sensitivity and peak frequency $\left(f_{c s}\right)$ determination

All subjects were instructed to avoid substances influencing the cardiovascular system (e.g. caffeine, 
alcohol) and smoking 12 hours before examination. All subjects were examined under standardized conditions in a quiet room from 8 to 12 a.m. They rested in the supine position for $20 \mathrm{~min}$ prior to the measurement; thereafter they were instructed to lie comfortably in the supine position and not to speak or move unnecessarily during the following 1 hour of recording.

Finger arterial blood pressure was continuously recorded by Finapres (Ohmeda 2300, USA) for one hour. The analogue output signal was transferred into a PC by an analog-to-digital converter (PCL-711, Advantech, Taiwan) and a blood pressure waveform was sampled at a frequency of $500 \mathrm{~Hz}$. Beat-to-beat values of the inter-beat interval (IBI), systolic and diastolic blood pressures (SBP, DBP) were determined, interpolated by the cubic spline function, resampled at $10 \mathrm{~Hz}$, and filtered by a low-pass filter with a $0.8 \mathrm{~Hz}$ cut-off frequency. Finally, the sampling frequency was reduced to $2 \mathrm{~Hz}$. Prior to further processing, the very low frequency components of the signals were suppressed by a high-pass filter with a cut-off frequency of $0.02 \mathrm{~Hz}$.

With respect to some disturbances in some signals at the beginning or at the end of the recording, only 42 minutes of the recordings were analysed starting $1.5 \mathrm{~min}$ after the beginning of the recording. Mean values of IBI, SBP and DBP were calculated. Forty-two minutes' recordings were divided into 14 three-minute segments. The autocorrelation and cross-correlation functions of IBI and SBP were calculated. In the next step the power spectra, cross-spectra and coherence of correlation functions of the IBI and SBP spectra were calculated by Fast Fourier Transform (Honzíková et al. 2003).

The peak frequency $\left(\mathrm{f}_{\mathrm{cs}}\right)$ was determined as follows: maximal power in cross-spectra between variability in blood pressure and inter-beat intervals in the low-frequency range of $0.06-0.12 \mathrm{~Hz}$ was determined and its frequency was taken as $\mathrm{f}_{\mathrm{cs}}$. BRS was determined in this range as the gain of the transfer function between variations in systolic blood pressure and inter-beat intervals (Zavodna et al. 2006). We limited the frequency range with respect to the spontaneous respiration of the subjects. We wanted to minimize the influence of respiration on assessed transfer function, i.e. to eliminate the respiratory sinus arrhythmia from analysis (Bothova et al. 2010) - the upper border was set lower than the respiration frequency of subjects (about $0.15 \mathrm{~Hz}$ ), and to minimize the influence of slow variations in respiratory pattern the lower limit of analysed range was set to $0.06 \mathrm{~Hz}$ (Honzikova et al. 1995). We could not exclude the possibility that slower breathing patterns in the 0.06$0.12 \mathrm{~Hz}$ range could influence BRS values (i.e., it could lead to higher BRS values). However, we have no information on any difference in the breathing patterns between compensated diabetics and healthy subjects; we therefore suggest that the possible influence of the breathing pattern on BRS measures was comparable in both groups analysed.

\section{Statistical analysis}

Mean values and standard deviations of BRS and $f_{c s}$ were calculated. The significance of the differences was evaluated by the Mann-Whitney test, and correlations were evaluated by Spearman correlation coefficient. Logistic regression analysis was applied for evaluation of the association between decreased BRS and $\mathrm{f}_{\mathrm{cs}}$ and the risk of autonomic dysfunction in type 1 diabetes mellitus (Honzík et al. 2009, 2010). The predicting power of BRS, $f_{c s}$, and a combination of both factors (index Fz) for autonomic dysfunction in diabetes mellitus was evaluated by sensitivity and specificity. Fz values were calculated by logistic regression from equation

$$
\mathrm{Fz}=1 /(1+\exp (-\mathrm{z}))
$$

where

$$
\mathrm{z}=3.09-0.013 * \text { BRS }-0.027 * \mathrm{f}_{\mathrm{cs}} \text {. }
$$

The coefficients in this equation were determined by logistic regression.

The optimal critical values were determined by the receiver operating curve (ROC), i.e., a plot of sensitivity versus specificity for moving critical values in steps as a value at which the highest combination of sensitivity and specificity was reached (Krontorádová et al. 2008, Honzík et al. 2010).

\section{Results}

The differences in circulatory parameters between patients suffering from T1DM and the controls are presented in Table 1. Mean values of individual parameters were calculated from whole beat-to-beat resting recordings of blood pressure lasting for 42 minutes. All subjects had physiological values of blood pressure and inter-beat intervals and there were no differences in these characteristics between both groups. 
Table 1. Differences in circulatory parameters between patients with type I diabetes mellitus (T1DM) and healthy controls.

\begin{tabular}{|c|c|c|c|}
\hline & T1DM & Controls & $\begin{array}{l}\text { P (Mann- } \\
\text { Whitney) }\end{array}$ \\
\hline $\begin{array}{l}\text { Number of } \\
\text { subjects }\end{array}$ & 14 & 14 & NS \\
\hline $\mathrm{SBP}[\mathrm{mm} \mathrm{Hg}]$ & $112.8 \pm 12.1$ & $117.3 \pm 11.0$ & NS \\
\hline $\mathrm{DBP}[\mathrm{mm} \mathrm{Hg}]$ & $58.6 \pm 8.5$ & $59.5 \pm 5.0$ & NS \\
\hline$I B I[m s]$ & $825 \pm 107$ & $876 \pm 112$ & NS \\
\hline$B R S[\mathrm{~ms} / \mathrm{mm} \mathrm{Hg}]$ & $10.3 \pm 4.4$ & $14.6 \pm 7.1$ & $\mathrm{p}=0.06$ \\
\hline$f_{c s}[m H z]$ & $88.8 \pm 6.7$ & $93.7 \pm 3.8$ & $\mathrm{p}<0.05$ \\
\hline coherence & $0.75 \pm 0.10$ & $0.74 \pm 0.10$ & NS \\
\hline
\end{tabular}

SBP, systolic blood pressure; DBP, diastolic blood pressure; IBI, inter-beat interval; $B R S$, baroreflex sensitivity; $f_{c s}$ frequency of a maximum of the power in cross-spectra between variability in blood pressure and inter-beat intervals; NS, non-significant.
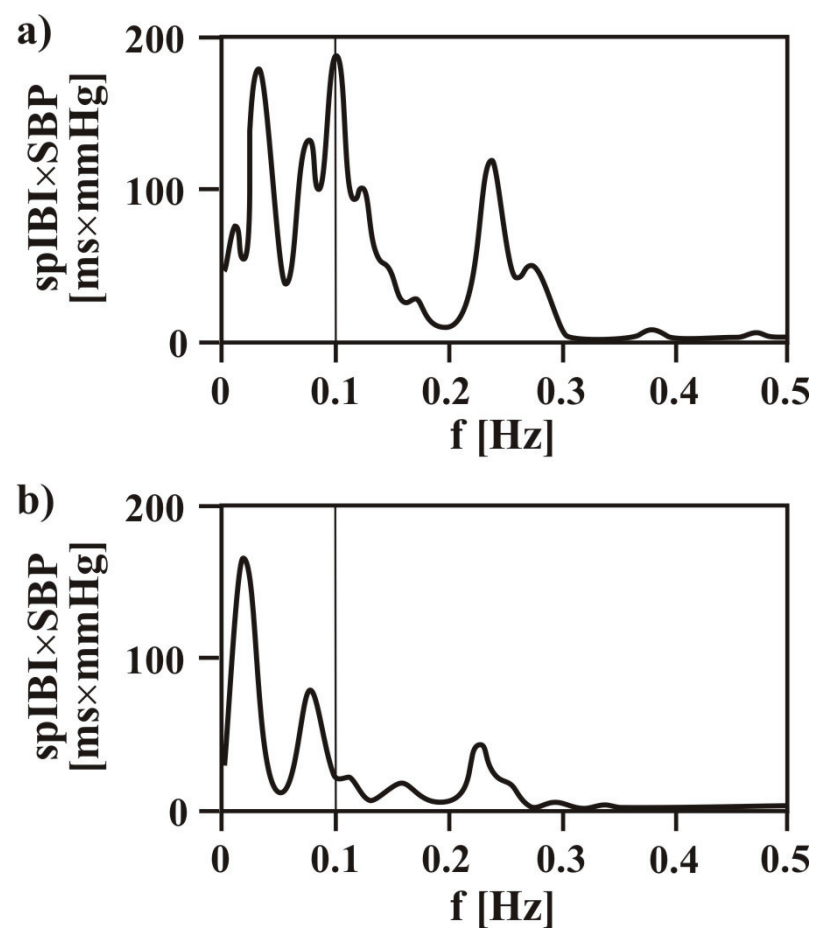

Fig. 1. Examples of determination of spectral peak frequency in a range of frequencies between 0.06 and $0.12 \mathrm{~Hz}$ in crossspectra of systolic blood pressure and inter-beat intervals (spIBI*SBP) in two subjects: a) control subject with maximum power at $0.1 \mathrm{~Hz}$; b) T1DM patient with maximum power at $0.07 \mathrm{~Hz}$.

Determination of individual values of BRS and $\mathrm{f}_{\mathrm{cs}}$ required a different procedure. The whole recording (42 min) was divided into 14 segments lasting for 3 minutes in which $f_{c s}$ and BRS were determined by spectral analysis. The frequency $f_{c s}$ was determined in a frequency range between 0.06 to $0.12 \mathrm{~Hz}$ at a maxima of power in the cross-spectra of systolic blood pressure and inter-beat intervals (coherence was higher than 0.5). Examples of the cross-spectra of systolic blood pressure and inter-beat intervals in two subjects are given in Figure 1. The maximum of power is at $0.1 \mathrm{~Hz}$ in one control subject (Fig. 1a, upper curve) and at $0.07 \mathrm{~Hz}$ in a T1DM (Fig. 1b, lower curve). BRS values were calculated at these frequencies. The resulting individual values of $\mathrm{f}_{\mathrm{cs}}$ and BRS were calculated as a mean of these 14 values determined in each recording. Finally, BRS and $\mathrm{f}_{\mathrm{cs}}$ between the T1DM group and the controls were compared. The frequency $f_{c s}$ was significantly lower in diabetic patients comparing to controls $(p=0.045)$ (Table 1). BRS also tended to be decreased in T1DM but this difference was marginally non-significant $(p=0.06) \quad$ (Table 1). Because BRS fluctuated similarly as blood pressure and IBI and an individual mean was calculated only from 14 values, we tested the reliability of the calculated values of BRS by shifting the beginning of the analysed recording. The results were comparable with $\mathrm{p}$-values varying from $p=0.04$ to $p=0.09$. Concerning the effect of shifting the beginning of the analysed recording on $\mathrm{f}_{\mathrm{cs}}$, this value was in any case significantly lower in diabetic patients comparing with the controls, $\mathrm{p}$ value varied in a range of 0.01-0.05. We present the results of calculation at a standard beginning in all subjects. The results were not influenced by coherence, because coherence was similar in both groups (Table 1).

Table 2. Sensitivity and specificity of baroreflex sensitivity (BRS), frequency of a maximum of the power in cross-spectra between variability in blood pressure and inter-beat intervals in a lowfrequency range $\left(f_{c s}\right)$, and a combination of BRS and $f_{c s}$ (index Fz) determined for critical values at which the highest combination of sensitivity and specificity was reached.

\begin{tabular}{lccc} 
Predictor & Specificity & Sensitivity & Critical value \\
\hline$B R S$ & $71.4 \%$ & $64.3 \%$ & $11.34 \mathrm{~ms} /$ \\
& & & $\mathrm{mm} \mathrm{Hg}$ \\
$f_{c s}$ & $64.3 \%$ & $64.3 \%$ & $91.1 \mathrm{mHz}$ \\
$F z(B R S$ & $71.4 \%$ & $71.4 \%$ & 0.49 \\
and $\left.f_{c s}\right)$ & & & \\
\hline
\end{tabular}

The correlation between BRS and $\mathrm{f}_{\mathrm{cs}}$ was not significant in any of the groups, controls and T1DM; on the other hand, it was significant in all subjects together (Table 3).

The discriminating performance of $\mathrm{f}_{\mathrm{cs}}, \mathrm{BRS}$, and both these indices combined as index $\mathrm{Fz}$ between 
Table 3. Spearman's correlations between baroreflex sensitivity (BRS) and frequency of a maximum of the power in cross-spectra $\left(f_{C S}\right)$ in the whole group and in the particular subgroups.

\begin{tabular}{lcc}
\hline Group & Spearman R & p-value \\
\hline All subjects & 0.512 & $<0.005$ \\
Controls & 0.429 & $\mathrm{NS}$ \\
T1DM & 0.481 & $\mathrm{NS}$ \\
\hline
\end{tabular}

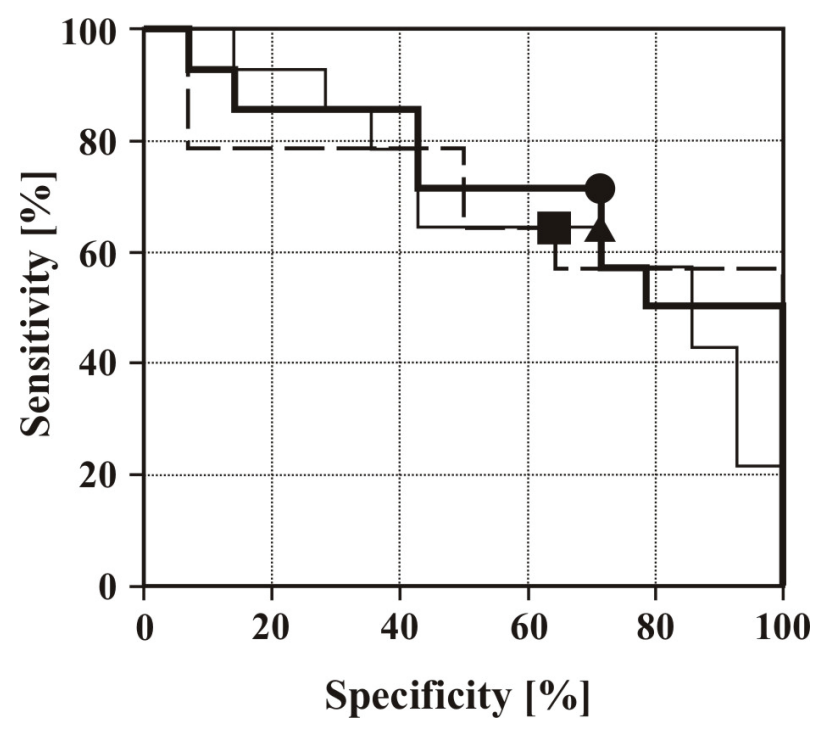

Fig. 2. Receiver operating curves of baroreflex sensitivity (BRS, full thin line), of spectral peak frequency in a range between 0.06 and 0.12 ( $f_{\mathrm{cs}}$, dashed line), and of combination of both factors (index Fz, full thick line). Optimal critical values: BRS (triangle), $\mathrm{f}_{\mathrm{cs}}$ (square), and $\mathrm{Fz}$ (black circle).

diabetics and controls was compared after determination of their sensitivity and specificity for discrimination between diabetics and controls. The optimal critical values for $\mathrm{BRS}, \mathrm{f}_{\mathrm{cs}}$, and a combination of both factors (Fz) were determined (Table 2, Fig. 2). A combination of sensitivity and specificity reached the highest value for the combined index Fz (Table 2).

\section{Discussion}

The major finding of this study is the shift of the central frequency of the cross-spectrum of blood pressure and heart rate fluctuations towards a lower value in young diabetic patients as a new characteristic of baroreflex impairment in this high-risk group.

There is general agreement that baroreflex control of heart rate is impaired in patients with type 1 diabetes mellitus suffering from cardiovascular autonomic neuropathy. Several studies showed that decreased BRS belongs among signs of CAN in both adults (Martiniskova et al. 2009) and children (Boysen et al. 2007, Dalla Pozza et al. 2007, Krause et al. 2009), and that the degree of its decrease is related to the duration of the disease (Dalla Pozza et al. 2007) and to the quality of the control of glycaemia examined as HbA1c (Krause et al. 2009). It has to be taken into account that there are more mechanisms affecting baroreflex sensitivity besides CAN. For example, changes of the mechanical properties and function of the arterial wall (e.g. increased arterial stiffness (Labrova et al. 2005, Atabek et al. 2006), impaired endothelial function (Poredos et al. 2006) may lead to changes in afferent signalling. Our finding of a marginally lower BRS $(\mathrm{p}=0.06)$ in diabetic patients without CAN detectable by Ewing's tests is in agreement with this fact and indicates a high sensitivity of the BRS method to the detection of early autonomic function impairment.

The frequency of the spectral peak in the crossspectra of systolic blood pressure and heart rate fluctuations in the low frequency range between 0.06 and $0.12 \mathrm{~Hz}\left(\mathrm{f}_{\mathrm{cs}}\right)$ is a new measure examined in our study characterizing baroreflex control of heart rate. We showed that this measure was even better in the detection of baroreflex dysfunction compared to BRS measurement with both indices being decreased in young patients with type 1 diabetes mellitus. The two factors, BRS and $\mathrm{f}_{\mathrm{cs}}$, did not significantly correlate within both controls and diabetic patient groups. On the other hand, they did correlate in the entire prognosis data set. The classification improvement by combining $\mathrm{f}_{\mathrm{cs}}$ and BRS was reflected at optimal critical values in the ROC characteristics. These characteristics suggest a partly independent contribution of $\mathrm{f}_{\mathrm{cs}}$ and BRS to the two-factor logistic regression prognosis model. This fact can be explained by additive involvement of more factors related not only to BRS and to the development of CAN, but also to the shift of the resonance frequency of the spectral peak in the cross-spectra of systolic blood pressure and heart rate fluctuations related to the regulatory properties of baroreflex control of peripheral resistance (Van De Vooren 2007).

We analysed recordings from patients without CAN based on the standardly used Ewing battery of tests. We suggest that the observed inter-group differences in cardiovascular control could be the very early signs of an ongoing process of cardiovascular dysregulation detectable later by less sensitive methods. It could only be hypothesized that the mechanisms found in a 
developed CAN in diabetic patients might influence the time lag in the feedback control of blood pressure, and this effect might occur very early. They might involve an autoimmune reaction in the sympathetic ganglia (Duchen 1980) or in the adrenal medulla, and the sympathetic and/or parasympathetic nervous system dysbalance (Rabinowe 1990, Vinik 1995). Sorbitol created from glucose abundance is accumulated in Schwann cells of patients with diabetes. It cannot pass through the membrane and induces cell oedema leading to possible functional changes (Suzuki et al. 1994).

In conclusion, an early diagnosis of CAN is important for intensive therapeutic intervention in diabetic patients to reduce the future risk of cardiovascular complications. The frequency of the spectral peak in the cross-spectra of systolic blood pressure and heart rate fluctuations $\left(\mathrm{f}_{\mathrm{cs}}\right)$ is decreased in young diabetics and could provide a new diagnostic tool for the detection of autonomic nervous system impairment in these patients. The method of joint evaluation of BRS and $f_{c s}$ as an integrated index presented by ourselves seems to be more sensitive than the usual tests for autonomic neuropathy as documented by ROC curves and offers advancement in the risk stratification of diabetic patients. It might also be suggested that actual monitoring (e. g., in the form of a repeated measurement within years) of the BRS in terms of gain and LF central frequency might be a sensitive tool for the early detection of a neuropathy. On the other hand, a major shortcoming of this study is a small size of the tested groups of controls and patients. More studies with larger samples confirming the present findings are needed.

\section{Conflict of Interest}

There is no conflict of interest.

\section{Acknowledgements}

Supported by grants: MSM 0021622402 from the Ministry of Education, Youth and Sports of the Czech Republic, VEGA No. 1/0033/11, and Project of the Centre of Excellence No. 26220120016.

\section{References}

ATABEK ME, KURTOGLU S, PIRGON O, BAYKARA M: Arterial wall thickening and stiffening in children and adolescents with type 1 diabetes. Diabetes Res Clin Pract 74: 33-40, 2006.

BOTHOVA P, HONZÍKOVÁ N, FIŠER B, ZÁVODNÁ E, NOVÁKOVÁ Z, KALINA D, HONZÍKOVÁ K, LÁBROVÁ R: Comparison of baroreflex sensitivity determined by cross-spectral analysis at respiratory and $0.1 \mathrm{~Hz}$ frequencies in man. Physiol Res 59 (Suppl 1): S103-S111, 2010.

BOYSEN A, LEWIN MAG, HECKER W, LEICHTER HE, UHLEMANN F: Autonomic function testing in children and adolescents with diabetes mellitus. Pediatr Diabetes 8: 261-264, 2007.

DALLA POZZA R, BECHTOLD S, BONFIG W, PUTZKER S, KOZLIK-FELDMANN R, SCHWARZ HP, NETZ H: Impaired short-term blood pressure regulation and autonomic dysbalance in children with type 1 diabetes mellitus. Diabetologia 50: 2417-2423, 2007.

DIETRICH A, ROSMALEN JGM, ALTHAUS M, VAN ROON AM, MULDER LJM, MINDERAA RB, OLDEHINKEL AJ, RIESE H: Reproducibility of heart rate variability and baroreflex sensitivity measurements in children. Biol Psychol 85: 71-78, 2010.

DUCHEN LW, ANJORIN A, WATKINS PJ, MACKAY JD: Pathology of autonomic neuropathy in diabetes mellitus. Ann Int Med 92 (Suppl 1): 301-303, 1980.

EWING DJ, CLARKE BF: Diagnosis and management of diabetic autonomic neuropathy. Brit Med J 285: 916-918, 1982.

HONZIK P, KUCERA P, HYNCICA O, JIRSIK V: Area under receiver operating characteristic as a sorting problem. In: 15th International Conference on Soft Computing. M RADEK (ed), Brno Univ Technology VUT Press, Brno, 2009, pp 277-282.

HONZÍK P, KŘIVAN L, LOKAJ P, LÁBROVÁ R, NOVÁKOVÁ Z, FIŠER B, HONZÍKOVÁ N: Logit and fuzzy models in data analysis: estimation of risk in cardiac patients. Physiol Res 59 (Suppl 1): S89-S96, 2010.

HONZIKOVA N, PENAZ J, FISER B, HONZIK J: The relationship between spontaneous fluctuations in circulation and depth and rate of respiration. Homeostasis 36: 165-169, 1995. 
HONZÍKOVÁ N, PEŇÁZ J, FIŠER B: Individual features of circulatory power spectra in man. Eur J Appl Physiol 59: 430-434, 1990.

HONZÍKOVÁ N, KRTIČKA A, NOVÁKOVÁ Z, ZÁVODNÁ E: A dampening effect of pulse interval variability on blood pressure variations with respect to primary variability in blood pressure during exercise. Physiol Res 52: 299-309, 2003.

JAVORKA M, JAVORKOVA J, TONHAJZEROVA I, JAVORKA K: Parasympathetic versus sympathetic control of the cardiovascular system in young patients with type 1 diabetes mellitus. Clin Physiol Funct Imaging 25: 270274, 2005.

JAVORKA M, LAZAROVA Z, TONHAJZEROVA I, TURIANIKOVA Z, HONZIKOVA N, FISER B, JAVORKA K, BAUMERT M: Baroreflex analysis in diabetes mellitus: linear and nonlinear approaches. Med Biol Eng Comput 49: 279-288, 2011.

JÍRA M, ZÁVODNÁ E, HONZÍKOVÁ N, NOVÁKOVÁ Z, FIŠER B: Baroreflex sensitivity as an individual characteristic feature. Physiol Res 55: 349-351, 2006.

JÍRA M, ZÁVODNÁ E, NOVÁKOVÁ Z, FIŠER B, HONZÍKOVÁ N: Reproducibility of blood pressure and inter-beat interval variability in man. Physiol Res 59 (Suppl 1): S113-S121, 2010.

KRAUSE M, RÜDIGER H, BALD M, NÄKE A, PADITZ E: Autonomic blood pressure control in children and adolescents with type 1 diabetes mellitus. Pediatr Diabetes 10: 255-263, 2009.

KRONTORÁDOVÁ K, HONZÍKOVÁ N, FIŠER B, NOVÁKOVÁ Z, ZÁVODNÁ E, HRSTKOVÁ H, HONZÍK P: Overweight and decreased baroreflex sensitivity as independent risk factors for hypertension in children, adolescents, and young adults. Physiol Res 57: 385-391, 2008.

LABROVA R, HONZIKOVA N, MADEROVA E, VYSOCANOVA P, NOVAKOVA Z, ZAVODNA E, FISER B, SEMRAD B: Age-dependent relationship between the carotid intima-media thickness, baroreflex sensitivity, and the inter-beat interval in normotensive and hypertensive subjects. Physiol Res 54: 593-600, 2005.

LAEDERACH-HOFMANN K, MUSSGAY L, WINTER A, KLINKENBERG N, RÜDDEL H: Early autonomic dysfunction in patients with diabetes mellitus assessed by spectral analysis of heart rate and blood pressure variability. Clinical Physiology 19: 97-106, 1999.

LUCINI D, ZUCCOTTI G, MALACARNE M, SCARAMUZZA A, RIBONI S, PALOMBO C, PAGANI M: Early progression of the autonomic dysfunction observed in pediatric type 1 diabetes mellitus. Hypertension 54: 987994, 2009.

MARTINISKOVA Z, KUCERA P, SYKORA M, KOLLAR B, GOLDENBERG Z, TURCANI P: Baroreflex sensitivity in patients with type I diabetes mellitus. Neuroendocrinol Lett 30: 491-495, 2009.

NAKAHARA T, KAWADA T, SUGIMACHI M, MIYANO H, SATO T, SHISHIDO T, YOSHIMURA R, MIYASHITA H, INAGAKI M, ALEXANDER J, SUNAGAWA K: Neuronal uptake affects dynamic characteristics of heart rate response to sympathetic stimulation. Am J Physiol Regul Integr Comp Physiol 277: R140-R146, 1999.

PENAZ J: The blood pressure control system: a critical and methodological introduction. Bibliotheca Psychiatrica 144: 125-150, 1970.

POREDOS P, KEK LJUBEC A, POREDOS P, VISNOVIC-POREDOS A: Endothelial dysfunction predictor of structural changes of arterial wall in type I diabetes. Int Angiol 25: 280-286, 2006.

RABINOWE SL, BROWN FM, WATTS M, SMITH AM: Complement-fixing antibodies to sympathetic and parasympathetic tissues in IDDM: autonomic brake index and heart-rate variation. Diabetes Care 13: 10841088, 1990.

SAYERS BM: Analysis of heart rate variability. Ergonomics 16: 17-32, 1973.

SUZUKI E, YASUDA K, YASUDA K, MIYAZAKI S, TAKEDA N, INOUYE H, OMAWARI N, MIURA K: 1H-NMR analysis of nerve edema in the streptozotocin-induced diabetic rat. J Lab Clin Med 124: 627-637, 1994.

VAN DE VOOREN H, GADEMAN MGJ, SWENNE CA, TENVOORDE BJ, SCHALIJ MJ, VAN DER WALL EE: Baroreflex sensitivity, blood pressure buffering, and resonance: What are the links? Computer simulation of healthy subjects and heart failure patients. J Appl Physiol 102: 1348-1356, 2007. 
VINIK AI, MASER RE, MITCHELL BD, FREEMAN R: Diabetic autonomic neuropathy. Diabetes Care 26: 15531579, 2003.

VINIK AI, HOLLAND MT, LEICHTER SB, POWERS AC, PITTENGER GL, SUWANWALAIKORN S, STANSBERRY KB: Phospholipid and glutamic acid decarboxylase autoantibodies in diabetic neuropathy. Diabetes Care 18: 1225-1232, 1995.

WADWA RP: Cardiovascular disease risk in youth with diabetes mellitus. Rev Endocr Metab Disord 7: 197-204, 2006.

WESSELING KH, SETTELS JJ, WALSTRA HG, VAN ESCH HJ, DONDERS JJH: Baromodulation as the cause of short term blood pressure variability? In: Proceedings of the International Conference on Applications of Physics to Medicine and Biology. G ALBERI, Z BAJZLER, P BAXA (eds), Singapore, 1983, pp 247-276.

ZAVODNA E, HONZIKOVA N, HRSTKOVA H, NOVAKOVA Z, MOUDR J, JIRA M, FISER B: Can we detect the development of baroreflex sensitivity in humans between 11 and 20 years of age? Can J Physiol Pharmacol 84: 1275-1283, 2006. 